dựng hệ thống phòng, chống ĐQN rất hiệu quả bằng nhiều biện pháp như thành lập hội người có nguy cơ cao, tổ chức các đơn vị cấp cứu nhanh, giáo dục sức khỏe, thay đổi lối sống cho người có nguy cơ và đặc biệt là phổ biến giáo dục tới người dân những dấu hiệu cảnh báo sớm của ĐQN để khi có một trong các dấu hiệu nghi ngờ người bệnh có thể nhanh chóng nhận biết và nhờ sự can thiệp, hỗ trợ kịp thời từ người thân hoặc cán bộ y tế qua nhiêu kênh thông tin và biện pháp hỗ trợ khác nhau [1].

\section{KẾT LUÂN}

Trình độ học vấn có mối liên quan có ý nghĩa thống kê với kiến thức về dự phòng đột quy não của đối tượng nghiên cứu với $p<0,05$.

Nguồn thông tin nhận được về bệnh đột quy. não có mối liên quan có ý nghĩa thống kê với kiến thức về dự phòng đột quỵ. não của đối tượng nghiên cứu với $p<0,05$.

Các chỉ số xét nghiệm (HbA1C, Cholesterol, Triglycerid) có mối liên quan có ý nghĩa thống kê với kiến thức về dự phòng đột quỵ. não của đối tượng nghiên cứu với $p<0,05$.

Chưa tìm thấy có mối liên quan có ý nghĩa thống kê giữa tuổi, thời gian mắc bệnh, giới tính, nghề nghiệp, tiền sử gia đình có người mắc bệnh đột quy não với kiến thức về dự phòng bệnh của đối tượng nghiên cứu với p>0,05.

\section{TÀI LIÊU THAM KHẢO}

1. Bộ Y tế (2015). Quyết định phê duyệt Chiến lược quốc gia phòng, chống bệnh ung thứ, tim mạch, đái tháo đường, bênh phổi tắc nghẽn mạn tính, hen phế quản và các bênh không lây nhiếm khác, giai đoạn 2015 - 2025, Hà Nội.

2. Lê Thị Hương và cộng sự (2016). Tỷ lệ mắc đột quy tại 8 tỉnh thuộc 8 vùng sinh thái việt nam năm 2013-2014 và mộtt số yếu tố liên quan. Tạp chí nghiên cứu Y hoc, 104 (6), 1-6.

3. Trân Hồng Nhung (2014). Kiến thức thức hành phòng tai biến mạch máu não và một số yếu tố liên quan của người cao tuổi phường Đức Giang quận Long Biên Hà Nội, Đại hơc y tế công cộng.

4. Đinh Thi Yến (2017). Thay đổi nhân thức về đột quy não của người cao tuổi tại xã Giao Lac - Giao Thưy Nam Định sau can thiệp giáo dục sức khỏe. Luận văn thạc sĩ, trường Đại học Điều dưỡng Nam Định.

5. CDC (2014), Stroke Facts, Atlanta, USA, Centers for Disease Control and Prevention.

6. Cooper M.E., Jandeleit-Dahm K.A., Candido R. (2010). The Pathogenesis of Macrovascular Complications Including Atherosclerosis in Diabetes. Text book of Diabetes, Fourth Edition. Wiley Blackwell,637-649.

7. D. Mozaffarian \& et al. (2014). Heart disease and stroke statistics, a report from the American Heart Association, pp. 28-292.

8. Division of Diabetes Translation. and National Center for Chronic Disease Prevention and Health Promotion (2015). National Diabetes Statistics Report, 2014. Centers for Disease Control and Prevention, 1-12.

\title{
NGHIÊN CỨU CÁC CHỈ Số CHIỀU DÀI TRỤC NHÃN CẦ, Độ SÂU TIỀN PHÒNG, Độ DÀY GIÁC MẠC TRUNG TÂM VÀ Độ DÀY THỦY TINH THỂ TRÊN NGƯỜI VIÊTT NAM TỪ 46 ĐẾN 65 TUỔI
}

\author{
Nguyễn Thành Luân*, Nguyễn Thái Hà Dương**
}

\section{TÓM TẮT}

Mục tiêu: Xác định chỉ số chiều dài trục nhãn cầu, độ sâu tiền phòng, độ dày giác mạc trung tâm và độ dàythủy tinh thể trên người Việt Nam từ 46 đến 65 tuổi. Đánh giá một số yếu tố liển quan với các chỉ số nhân trắc của nhãn câu nêu trên. Đối tượng và phương pháp: Mô tả cắt ngang trên 195 người Việt Nam từ 46-65 tuổi bằng MáyIOLMaster700 tại bệnh viện Mắt Trung ương. Kết quả: 195 người với 94 nam $(48,2 \%)$ và 101 nữ $(51,7 \%)$, chiều dài trục nhãn câu:

\footnotetext{
*Trường Đại học Kỹ thuật Y tế Hải Dương

**Trướng Đại học Y Dược, ĐH Quốc gia HN

Chịu trách nghiệm chính: Nguyễn Thành Luân

Email: nguyenthanhluan27291@gmail.com

Ngày nhận bài: 15/4/2021

Ngày phản bienj khoa học: 3/5/2021

Ngày duyệt bài: 21/5/2021
}

$23,13 \pm 0,66 \mathrm{~mm}$, độ sâu tiền phòng:3,15 $\pm 0,36$ $\mathrm{mm}$, độ dày giác mạc trung tâm $529,15 \mu \mathrm{m} \pm 30,57$ $\mu \mathrm{m}$, đồ dày thủy tinh thể : 4,38 $\pm 0,42 \mathrm{~mm}$. Chiều dài trục nhãn câu, độ sâu tiền phòng, độ dày giác mạc trung tâm giảm theo tuổi và lớn hơn ở nam giới với $\mathrm{p}<0,05$. Độ dày thủy tinh thể tăng dân theo tuổi, không có sự khác biệt giữa nam giới và và nữ giới. Kết luận: Chiều dài trục nhãn cầu, độ sâu tiền phòng, độ dày giác mac trung tâm và độ dày thủy tinh thể là các chỉ số có giá trị trong chẩn đoán và điêu trị nhiều bệnh lý của nhãn cầu. Nghiên cứu xác định các chỉ số này trên người Việt Nam, đóng góp vào các chỉ số nhân trắc trên nhãn câu bình thường theo giới và các nhóm tuổi, làm tiêu chuẩn để so sánh với các trường hợp bệnh lý.

Tứ khóa: Chiêu dài trục nhãn câu, độ sâu tiền phòng, độ dày giác mạc, độ dày thủy tinh thể.

\section{SUMMARY \\ RESEARCH ON MEASUREMENTS OF OCULAR}




\section{AXIAL LENGTH, ANTERIOR CHAMBER DEPTH, CENTRAL CORNEAL THICKNESS AND LENS THICKNESS IN VIETNAMESE PEOPLE FROM THE AGE OF 46 TO 65}

Objectives: To determine the measurements of eyeball axial length, the depth of anterior chamber and central corneal thickness in Vietnamese people from the age of 46 to 65 . Assess several relevant factors in mentioned ophthalmic anthropometry. Subjects and method: Cross-sectional descriptive study in 195 Vietnamese people from the age of 46 to 65 by IOLMaster700 at National Institute of Ophthalmology. Results: 195 people including 94 males (48.2\%) and 101 females (51.7\%), eyeball axial length: $23.13 \pm 0.66 \mathrm{~mm}$, anterior chamber depth: $3.15 \pm 0.36 \mathrm{~mm}$, central corneal thickness: $529.15 \pm$ $30.57 \mu \mathrm{m}$, Lens thickness:4,38 $\pm 0,42 \mathrm{~mm}$. These three measurements decrease with age and were higher in males $(p<0.05)$. The eyeball axial length had positive correlation with anterior chamber depth and central corneal thickness. Lens thickness increases with age, there is no difference between men and women. Conclusion: Eyeball axial length, anterior chamber depth, central corneal thickness and lens thickness are valued in diagnosis and treatment in eye illnesses. This study determined these measurements in Vietnamese people, which contribute towards anthropometric indices of normal ophthalmology in genders and ages, playing a standard as comparing to cases of illnesses

Keywords: Eyeball axial length, anterior chamber depth, corneal thickness,Lens thickness.

\section{I. ĐẶT VẤN ĐỀ}

Trục nhãn cầu, độ sâu tiền phòng, độ dày giác mạc trung tâm và độ dày thủy tinh thểlà các chỉ số được quan tâm nhiêu trong nhãn khoa. Việc xác định các chỉ số này trong các nghiên cứu cung cấp cho bác sĩ nhãn khoa cơ sở thông tin quan trọng có giá trị trong chẩn đoán và điều trị nhiều bệnh lý của nhãn cầu. Nhiều nghiên cứu liên quan đến sự phân bố các chỉ số nhân trắc nhãn cầu đã được báo cáo ở các nước như: Trung Quốc, Hoa Kỳ, Đức[1],[2],[3]. Kết quả của những nghiên cứu này tạo ra cơ sở dữ liệu tham khảo quan trọng cho chẩn đoán và điều trị bệnh lý nhãn cầu. Tuy nhiên do các chỉ số nhân trắc nhãn cầu có thể bi ảnh hưởng bởi chủng tộc và di truyền nên không thể làm tiêu chuẩn chung áp dụng cho tất cả các quốc gia [4]. Vì vậy cần có các nghiên cứu riêng ở mối quốc gia để có được cơ sở dữ liệu phù hợp với đặc điểm hình thái hoc mỗi nước. Ở Viête Nam, cho đến nay đã có một số nghiên cứu nhân trắc học nhãn cầu nhưng chưa đầy đủ nghiên cứu ở các lứa tuổi khác nhau. Vì vậy cần có thêm nghiên cứu để hoàn thiện cơ sở dữ liệu các chỉ số nhân trắc trên nhãn cầu bình thường theo các nhóm tuổi, làm tiêu chuẩn để so sánh với các trường hợp bệnh lý.

Với mong muốn góp phần cung cấp thêm cơ sở dữ liệu về nhân trắc học nhãn cầu của người Việt Nam, chúng tôi tiến hành đề tài "Nghiên cứu các chỉ số chiều dài trục nhãn câu, độ sâu tiền phòng và độ dày giác mạc trung tâm trên người Việt Nam từ 46 đến 65 tuổi"

\section{II. ĐỐI TƯỢNG VÀ PHƯƠNG PHÁP NGHIÊN CỨU}

\section{1. Đối tượng nghiên cứu}

- 195 người Việt Nam (94 nam và 101 nũ) từ 46 tới 65 tuổi.

- Thời gian và địa điểm nghiên cứu: Từ tháng 62017 đến 8-2018 tại bệnh viện Mắt Trung ương.

Tiêu chuẩn lựa chọn: Đồng ý tham gia nghiên cứu, không phân biệt giới tính, là người Việt Nam sống trên lãnh thổ Việt Nam.

Tiêu chuẩn loại trừ: Có chấn thương mắt, phẫu thuật mắt trước đây, sẹo giác mạc, đục thủy tinh thể nặng, glôcôm có xuất huyết dịch kính, đang mắc các bệnh lý mắt cấp tính, cận cao >- 6D, viễn cao > +5D.

2. Phương pháp nghiên cứu: Nghiên cứu mô tả cắt ngang.

- Cõ mẫu: 195

\section{Các bước nghiên cứu:}

- Khám lâm sàng: thu thập thông tin theo mẫu phiếu khám.

- Xác định các chỉ số trục nhãn cầu, độ sâu tiền phòng, độ dày giác mạc trung tâm và độ dày thủy tinh thể bằng máy IOLMaster 700.

+ Độ sâu tiền phòng là khoảng cách từ mặt trước giác mạc đến mặt trước thủy tinh thể.

+ Chiều dài trục nhãn cầu: khoảng cách từ trung tâm mặt trước giác mạc tới điểm vàng.

+ Độ dày giác mạc trung tâm là khoảng cách từ trung tâm mặt trước giác mạc tới trung tâm mặt sau giác mạc.

+ Độ dày thủy tinh thểlà khoảng cách từ trung tâm mặt trước thủy tinh thểtới trung tâm mặt sau thủy tinh thể.

- Vào số liệu, phân tích số liệu bằng phần mềmSPSS 16.0 .

4. Đạo đức nghiên cứu: Nghiên cứu đã thông qua hội đồng Đạo đức trong nghiên cứu $Y$ sinh học, Trường Đại học $Y$ hà Nội chấp thuận về các khía cạnh đạo đức nghiên cứu.

\section{KẾT QUẢ NGHIÊN CỨU}

Trong 195 người với 94 nam (48,2\%) và 101 nữ $(51,7 \%)$ có độ tuổi trung bình $56,43 \pm 5,74$ tuổi chúng tôi thu được kết quả như sau:

1. Chiều dài trục nhãn câu: $23,13 \pm 0,66$ $(n=195)$ 
Bảng 1. Chiều dài trung binh của trự nhãn cầu theo tuổi

\begin{tabular}{|c|c|c|c|c|c|}
\hline Tuối & N & Chiêu dài TB (mm) & SD & Min(mm) & Max (mm) \\
\hline $46-50$ & 39 & 23,26 & 0,69 & 21,47 & 24,82 \\
\hline $51-55$ & 40 & 23,23 & 0,71 & 21,45 & 24,77 \\
\hline $56-60$ & 64 & 23,06 & 0,63 & 21,60 & 24,78 \\
\hline $61-65$ & 52 & 23,05 & 0,61 & 21,44 & 24,17 \\
\hline Chung & 195 & 23,13 & 0,66 & 21,44 & 24,82 \\
\hline p ANOVA test & & & 0,047 & & \\
\hline
\end{tabular}

Chiều dài trục nhãn cầu giảm theo độ tuổi. Khác biệt có ý nghĩa thống kê $(p<0,05)$.

Bảng 2. Chiều dài trung binh trục nhãn cầu theo giới tính

\begin{tabular}{|c|c|c|c|c|c|}
\hline Giới & N & Độ sâu TB (mm) & SD & Min (mm) & Max (mm) \\
\hline Nam & 94 & 23,37 & 0,60 & 21,6 & 24,78 \\
\hline Nữ & 101 & 22,90 & 0,62 & 21,44 & 24,82 \\
\hline Chung & 195 & 23,13 & 0,66 & 21,44 & 24,82 \\
\hline p T-test & & & 0,000 & & \\
\hline
\end{tabular}

Chiều dài trục nhãn cầu lớn hơn ở nam giới. Khác biệt có ý nghĩa thống kê $(p<0,001)$.

2. Độ sâu tiên phòng: $3,15 \pm 0,36 \mathrm{~mm}(\mathrm{n}=195)$

Bảng 3. Độ sâu trung binh tiền phòng theo tuổi

\begin{tabular}{|c|c|c|c|c|c|}
\hline Tuối & $\mathbf{N}$ & Dộ sâu tiền phòng TB $\mathbf{( m m})$ & SD & Min $(\mathrm{mm})$ & Max $(\mathrm{mm})$ \\
\hline $46-50$ & 39 & 3,25 & 0,33 & 2,59 & 3,89 \\
\hline $51-55$ & 40 & 3,23 & 0,45 & 2,18 & 4,61 \\
\hline $56-60$ & 64 & 3,12 & 0,33 & 2,32 & 4,14 \\
\hline $61-65$ & 52 & 3,04 & 0,33 & 2,30 & 3,70 \\
\hline Chung & 195 & 3,15 & 0,36 & 2,18 & 4,61 \\
\hline p ANOVA test & & & 0,000 & & \\
\hline
\end{tabular}

Độ sâu tiền phòng giảm đáng kể theo độ tuổi. Khác biệt có ý nghĩa thống kê $(p<0,001)$

Bảng 4. Độ sâu trung bình tiền phòng theo giới tính

\begin{tabular}{|c|c|c|c|c|c|}
\hline Giới & $\mathbf{N}$ & Độ sâu tiền phòng TB (mm) & SD & Min (mm) & Max (mm) \\
\hline Nam & 94 & 3,21 & 0,36 & 2,22 & 4,61 \\
\hline Nữ & 101 & 3,08 & 0,35 & 2,18 & 4,32 \\
\hline Chung & 195 & 3,15 & 0,36 & 2,18 & 4,61 \\
\hline p T-test & & & 0,000 & & \\
\hline
\end{tabular}

Độ sâu tiền phòng lớn hơn ở nam giới. Khác biệt có ý nghĩa thống kê $(p<0,001)$.

3. Độ dày giác mạc trung tâm: $529 \pm 30,56 \mu \mathrm{m}$ ( $n=195)$

Bảng 5. Độ dày truing binh giác mạc trung tâm theo tuổi

\begin{tabular}{|c|c|c|c|c|c|}
\hline Tuối & $\mathbf{N}$ & Độ dày giác mạc trung tâm TB $(\boldsymbol{\mu m})$ & $\mathbf{S D}$ & Min & Max \\
\hline $46-50$ & 39 & 535,63 & 27.52 & 483 & 630 \\
\hline $51-55$ & 40 & 533,20 & 29.32 & 429 & 589 \\
\hline $56-60$ & 64 & 526,39 & 35.35 & 460 & 613 \\
\hline $61-65$ & 52 & 524,59 & 26.22 & 474 & 584 \\
\hline Chung & 195 & 529,15 & 30.57 & 429 & 630 \\
\hline p ANOVA test & & & 0,04 & & \\
\hline
\end{tabular}

Đô dày giác mạc trung tâm trung bình giảm dần theo tuối. Khác biệt có ý nghĩa thống kê với $\mathrm{p}<0,05$.

Bảng 6. Độ dày giác mạc trung tâm trung bình theo giới tính

\begin{tabular}{|c|c|c|c|c|c|}
\hline Giới & $\mathbf{N}$ & $\begin{array}{c}\text { Độ dày giác mạc trung tâm } \\
\text { trung binhh TB }(\boldsymbol{\mu m})\end{array}$ & SD & Min $(\mu \mathrm{m})$ & Max $(\mu \mathrm{m})$ \\
\hline Nam & 94 & 538,36 & 31,15 & 460 & 613 \\
\hline Nữ & 101 & 520,58 & 27,43 & 429 & 630 \\
\hline Chung & 195 & 529,15 & 30,57 & 429 & 630 \\
\hline p T-test & & 0,000 & & \\
\hline
\end{tabular}

Độ dày giác mạc trung tâm lớn hơn ở nam giới. Khác biệt có ý nghĩa thống kê $(p<0,001)$.

4. Độ dày thủy tinh thể: $4,38 \pm 0,42 \mathrm{~mm}(\mathrm{n}=195)$

Bảng 7. Độ dày thưy tinh thể theo tuối 
TẠP CHÍ Y HỌC VIỆT NAM TẬP 503 - THÁNG 6 - SỐ 2 - 2021

\begin{tabular}{|c|c|c|c|c|c|}
\hline Tuối & $\mathbf{N}$ & Độ dày thủy tinh thế TB (mm) & SD & Min (mm) & Max (mm) \\
\hline $46-50$ & 39 & 4.2 & 0.45 & 1.15 & 5.01 \\
\hline $51-55$ & 40 & 4.34 & 0.42 & 3.36 & 5.55 \\
\hline $56-60$ & 64 & 4.42 & 0.4 & 3.31 & 5.57 \\
\hline $61-65$ & 52 & 4.49 & 0.35 & 3.51 & 5.15 \\
\hline Chung & 195 & 4.38 & 0.42 & 1.15 & 5.57 \\
\hline p ANOVA test & & 0,000 & & \\
\hline
\end{tabular}

Độ dày thủy tinh thế tăng theo độ tuối. Khác biệt có ý nghĩa thống kê $(p<0,001)$.

Bảng 8. Đố dày thưy tinh thể theo giới tính

\begin{tabular}{|c|c|c|c|c|c|}
\hline Giới & $\mathbf{N}$ & Độ sâu tiền phòng TB (mm) & SD & Min (mm) & Max (mm) \\
\hline Nam & 94 & 4.3855 & 0.38139 & 3.48 & 5.57 \\
\hline Nữ & 101 & 4.3856 & 0.44507 & 1.15 & 5.19 \\
\hline Chung & 195 & 4.3856 & 0.41515 & 1.15 & 5.57 \\
\hline p T-test & & & $>0,997$ & & \\
\hline
\end{tabular}

Không có sự khác biệt giữa độ dày thủy tinh thế ở nam giới và nữ giới $(p>0,05)$.

\section{BÀN LUÂN}

1. Chiêu dài trục nhãn câu, độ sâu tiền phòng và độ dày giác mạc trung tâm, độ dày thủy tinh thể. Sự phân bố chiêu dài trục nhãn cầu, độ sâu tiền phòng và độ dày giác mạc trung tâm, độ dày thủy tinh thể ở người Việt Nam ở lứa tuổi từ 46-65 chưa được nghiên cứu

Chiều dài trục nhãn cầu trong nghiên cứu này là: $23,13 \pm 0,66 \mathrm{~mm}(\mathrm{n}=195)$. Theo các nghiên cứu trên thế giới, chiều dài trục nhãn cầu thay đổi từ $23,13 \mathrm{~mm}$ đến $23,80 \mathrm{~mm}$,chiều dài trục nhãn cầu trung bình trong nghiên cứu của chúng tôi tương đồng với kết quả nghiên cứu trên người châu Á ở Iran, Trung Quốcvà nhỏhơn người Mỹ và Châu Âu[1],[2],[3],[5].

Độ sâu tiền phòng trong nghiên cứu này là $3,15 \pm 0,36 \mathrm{~mm}(\mathrm{n}=195)$. Kết quả của các nghiên cứu khác trên thế giớidao động từ 3,13 đến $3,41 \mathrm{~mm}[2],[3],[5]$. Như vậy độ sâu tiền phòng trong nghiên cứu của chúng tôi cũng tương đồng như nghiên cứu trên người Châu A và nhỏ hơn người châu Âu và Mỹ.

Kết quả nghiên cứu độ dày giác mạctrung tâm trung bình trong nghiển cứu của chúng tôi là $529,15 \pm 30,57 \mu \mathrm{m}$. Giá trị này tương đồng với kết quả của Hassan Hashemi trên người Iran $(528,5 \pm 35,5 \mu \mathrm{m})[6]$.

Độ dày thủy tinh thể trong nghiên cứu này là: $4,38 \pm 0,42 \mathrm{~mm}(\mathrm{n}=195)$. Trên thế giới đã có một số tác giả nghiên cứu đô dày thủy tinh thể ở các chủng tộc và lứa tuổi của đối nghiên cứu khác nhau cho kết quả độ dày thủy tinh thể thay đổi từ 4,28 mm đến 4,93 mm [1],[5].

Nguyên nhân đầu tiên của sự khác biệt về giá trị của các chỉ số trục nhãn cầu, độ sâu tiên phòng, độ dày giác mạc trung tâmvà độ dày của thủy tinh thểtrong các nghiên cứu là do độ tuổi của mẫu trong các nghiên cứu không giống nhau. Trong khi chiều dài trục nhãn cầu và độ sâu tiền phòng và độ dày giác mạc trung tâm giảm dần theo tuổi ở những người trên 40 tuổi, điêu này đã được khẳng định trong các nghiên cứuShufelt[2] và Hashemi[5],[6].Sự gia tăng độ dày thủy tinh thể do thoái hóa đã được nêu trong báo cáo của Praveen[7] Ngoài ra, so sánh các kết quả nghiên cứu trên người Trung Quốc và Iran với người Đức và Mỹ, có thể thấy được chiều dài trục nhãn cầu và độ sâu tiền phòng ở người châu Á nhỏ hơn người châu Âu và Bắc Mỹ trong cùng lứa tuổi. Sự khác biệt này có thể được giải thích bởi sự khác biệt về chủng tộc và di truyên[4].

2. Liên quan tới chiêu dài trục nhãn câu, độ sâu tiên phòng, độ dày giác mạc trung tầm và độ dày thủy tinh thể với tuổi và giới tính. Trong nghiên cứu này chiều dài trục nhãn câu, độ sâu tiên phòng, độ dày giác mạc trung tâm rút ngắn theo đô tuổi. Nhiều nghiên cứu khác cũng cho kết quả tương tự đã được báo cáo bởi Shufelt[2] và Hashemi[5],[6]. Sứ gia tăng độ dày thủy tinh thể do thoái hóa có thể là nguyên nhân chínhlàm giảm độ sâu tiền phòng, điều này đã được nêu trong báo cáo của Praveen [7].

Trong nghiên cứu này độ dày thủy tinh thể tăng theo độ tuổi. Các nghiên cứu khác cũng cho kết quả tươning tự đã được báo cáo bởi $\mathrm{He}$ [1] và Hashemi[6]. Sự gia tăng độ dày thủy tinh thể theo tuối có thể là do sự gia tăng các lớp sợi protein hình thành ở lớp bao (the capsule).

Chiều dài trục nhãn cầu và độ sâu tiền phòng và đô dày giác mạc trung tâm trong nghiên cứu này lớn hơn ở nam giới. Nhiều nghiên cứu của các tác giả khác cũng tìm thấy được mối liên hệ giữa các chỉ số này với giới tính. Các nghiên cứu cho kết quả các chỉ số này ở nam giới lớn hơn nữ giới[1],[2],[5],[6].

Độ dày thủy tinh thể trong nghiên cứu này không có sự khác biệt giữa nam giới và nữ giới. 
Nhiều nghiên cứu khác cho kết quả khác nhau về mối liên hệ giữa độ dày thủy tinh thể và giới tính có kết quả trái ngược nhau, và thậm chí trong nghiên cứu của He và cộng sự, giá trị này được báo cáo lớn hơn ở phụ nữ[1],[5].

\section{KẾT LUẬN}

Trong nghiên cứu của chúng tôi, lần đầu tiên chỉ số nhân trắc vềchiều dài trục nhãn câuu, độ sâu tiền phòng, độ dày giác mạc trung tâm và độ dày thủy tinh thểđược xác định ở người Việt Nam 46-65 tuổi. So với kết quả của các nghiên cứu được tiến hành trên thế giới chỉ số này ở người Việt Nam 46-65 tuổi tương đồng với kết quả nghiển cứu ở trên người châu Á và nhỏ hơn các chỉ số được nghiên cứu trên người châu Âu và Mỹ. Chiều dài trục nhãn câu, độ sâu tiền phòng, độ dày giác mạc trung tâm giảm theo tuổi và cao hơn ở nam giới so với nữ giới.Độ dày thủy tinh thể tăng dần theo tuổi và không có sự khác biệt giữa nam giới và nữ giới.

\section{TÀI LIẸU THAM KHẢO}

1. Mingguang He, Wenyong Huang, Yuetao Li và công sứ (2009). Refractive error and biometry in older Chinese adults: the Liwan eye study. Investigative ophthalmology \& visual science, 50 (11), 5130-5136
2. Chrisandra Shufelt, Samantha Fraser-Bell, Mei Ying-Lai và công sứ (2005). Refractive error, ocular biometry, and lens opalescence in an adult population: the Los Angeles Latino Eye Study. Investigative ophthalmology \& visual science, 46 (12), 4450-4460.

3. Maria Teresa Zocher, Jos J Rozema, Nicole Oertel và cộng sự (2016). Biometry and visual function of a healthy cohort in Leipzig, Germany. BMC ophthalmology, 16 (1), 79.

4. Nicola S Logan, Leon N Davies, Edward AH Mallen và cộng sứ (2005). Ametropia and ocular biometry in a UK university student population. Optometry \& Vision Science, 82 (4), 261-266.

5. Hassan Hashemi, Mehdi Khabazkhoob, Mohammad Miraftab và cộng sự (2012). The distribution of axial length, anterior chamber depth, lens thickness, and vitreous chamber depth in an adult population of Shahroud, Iran. BMC ophthalmology, 12 (1), 50.

6. Hassan Hashemi, Soheila Asgari, Shiva Mehravaran và cộng sự (2011). The distribution of corneal thickness in a 40-to 64-year-old population of Shahroud, Iran. Cornea, 30 (12), 1409-1413.

7. MR Praveen, AR Vasavada, SK Shah và cộng sự (2009). Lens thickness of Indian eyes: impact of isolated lens opacity, age, axial length, and influence on anterior chamber depth. Eye, 23 (7), 1542.

8. Sora Hahn, Stanley Azen, Mei Ying-Lai và cộng sự (2003). Central corneal thickness in Latinos. Investigative ophthalmology \& visual science, 44 (4), 1508-1512.

\section{KHẢO SÁT NỒNG Đô PROTEIN PHẢN ỨNG C Ở BỆNH NHÂN ĐÁI THÁO ĐƯờNG TÍP 2 Có BỆNH THẬN MẠN}

Bùi Hữu Hoàng1, Đào Bùi Quý Quyền ${ }^{2}$, Lê Việt Thắng ${ }^{3}$

\section{TÓM TẮT}

Mục tiêu: Xác định nồng độ hs-CRP huyết tương ở bệnh nhân đái tháo đường típ 2 có bệnh thận mạn. Đối tượng và phương pháp: Nghiên cứu cắt ngang trên 156 đối tượng bao gồm 98 bệnh nhân ĐTĐ típ 2 có BTMT và 58 bệnh nhân không có BTMT. Tất cả các bệnh nhân được định lượng nồng độ hs-CRP huyết tương theo phương pháp đo độ đục phản ứng miền dịch. Kết quả: Nồng độ hs-CRP huyết tương trung bình ở nhóm ĐTĐ có BTMT là 2,34 $(1,31-3,96) \mathrm{mg} / \mathrm{L}$, cao hơn nhóm không có BTMT là $1,7 \quad(0,78-3,08)$ $\mathrm{mg} / \mathrm{L}, \mathrm{p}<0,05$. Tỷ lê bênh nhân ĐTĐ có BTMT tăng hs-CRP là $17,3 \%$ cao hơn nhóm không có BTMT là $1,7 \%, p<0,05$. Nhóm bệnh nhân ĐTÐ có BTMT kèm

${ }^{1}$ Bênh viên Nhân dân 115

${ }^{2}$ Bềnh viện Chợ Rẫy, TPHCM

${ }^{3}$ Họ viến Quấn y

Chịu trách nhiệm chính: Lê Việt Thắng

Email: lethangviet@yahoo.com.uk

Ngày nhận bài: 4/4/2021

Ngày phản biên khoa hoc: 8/5/2021

Ngày duyệt bài: 20/5/2021
RLLP máu; kiểm soát glucose máu kém; có biến chứng khác ngoài thận có nồng độ hs-CRP cao hơn nhóm không có đặc điểm trên, $p<0,05$. Kết luận:Tổn thương thận ở người bệnh ĐTĐ típ 2 làm tăng nồng độ hs-CRP huyết tương.

Tư khóa: Đái tháo đường típ 2, Bệnh thận mạn tính, Protein phản ứng $\mathrm{C}$ độ nhạy cao.

\section{SUMMARY \\ SURVEY ON CONCENTRATION OF PLASMA \\ HS-CRP IN TYPE 2 DIABETIC MELLITUS PATIENTS WITH CHRONIC NEPHROPATHY}

Objectives: To determine of plasma hs-CRP levels in type 2 diabetic mellitus (DM) with chronic nephropathy $(\mathrm{CN})$. Subjects and Methods: Crosssectional study on 156 subjects including 98 patients diagnosed type 2 DM with $\mathrm{CN}$ and 58 patients without CN. Plasma hs-CRP levels were quantified by immunoassay turbidity in al the patients. Results: The median plasma hs-CRP concentration in the DM group with CN was $2.34(1.31-3.96) \mathrm{mg} / \mathrm{L}$, higher than the group without $\mathrm{CN}$ was $1.7(0.78-3.08) \mathrm{mg} / \mathrm{L}$, $\mathrm{p}<0.05$. The proportion of serum hs-CRP increase inDM patients with $\mathrm{CN}$ was $17.3 \%$ higher than that of 